\title{
El clickbait y su influencia en la modificación de la estructura de la noticia en el Perú
}

\section{Clickbait and its influence on news structure changes in Peru}

Recibido: $11 / 08 / 2020$

Aceptado: 13/11/2020

Publicado: 30/11/2020
Juan Pablo Peña Salas u201412906@upc.edu.pe https://orcid.org/0000-0003-0904-6470 Universidad Peruana de Ciencias Aplicadas (Perú)

Resumen: El uso de titulares clickbait se ha vuelto común en el mundo periodístico, combinando estrategias del marketing para captar la atención de potenciales lectores, como el uso de signos de interrogación o apelando a la incertidumbre o a las emociones para lograr su cometido. El presente trabajo de investigación busca entender cómo el clickbait (como recurso del periodismo digital) ha alterado los criterios de jerarquización tradicionales, eliminando el uso de estructuras como la "pirámide invertida". Como metodología se analizó la plataforma digital de dos medios (uno de prensa radial y otro de prensa televisiva) para identificar cómo utilizan el clickbait y el de tipo de orden jerárquico, así como sus características, tales como el uso de citas y la sección en que se puede encontrar la nota en mención.

Palabras clave: Clickbait, Periodismo digital, Jerarquización informativa, Géneros periodísticos, Nota informativa. 
Abstract: The use of clickbait headlines has become common in journalism, combining marketing strategies to capture the attention of potential readers, such as the use of question marks or appealing to doubt or emotions to achieve its goal. This research work seeks to understand how the clickbait (as a resource of digital journalism) has altered traditional hierarchical criteria, instead of using structures such as "the inverted pyramid". As a methodology, the digital platform of two media, one of the radio press and the other of the television press, was analyzed to identify how they used clickbait and the type of hierarchical order, as well as their characteristics, such as the use of quotes and the section.

Key words: Clickbait, Digital journalism, Information hierarchy, Journalistic genres, Briefing notes.

\section{Introducción}

En pleno siglo XXI, luego de más de 20 años de la llegada de la Internet, los medios periodísticos se han visto en la necesidad de adaptarse a esta tendencia, implementando recursos propios del mundo digital para promover su contenido. Actualmente, el uso de lo multimedia o el hipertexto se ha vuelto indispensable, no sólo porque facilitan el trabajo sintetizador y de investigación del periodista, sino también porque promueven una correcta navegación del usuario a través de la web del medio para que este pueda informarse adecuadamente. La Internet también colaboró con el factor inmediatez, logrando que los contenidos se compartan con mayor rapidez, facilidad y llegada a más público. Sin embargo, también se han adoptado recursos como el clickbait que, al contrario de promover el correcto uso de la información, podría estar afectándola.

El clickbait, como recurso digital, está alterando los criterios de jerarquización en el periodismo digital, con el objetivo de generar más vistas para los medios que lo utilizan, pues su objetivo (más que informativo) es comercial al buscar más la interacción (García et al., 2017, p. 1265). Esto puede haber afectado la calidad de contenido que ofrecen en sus versiones web. En ese sentido, el presente artículo analiza las plataformas digitales de dos medios de comunicación (radiofónico y televisivo), pioneros en la incursión en la Internet en el país (Yezers'ka \& Zeta, 2016, p. 18). 
Por otro lado, es importante para la comunidad periodística conocer cómo es que el clickbait altera la estructura de las notas informativas. El orden jerárquico tradicional parte de responder una serie de preguntas: ¿quién?, ¿cómo?, ¿cuándo?, ¿dónde? y ¿por qué?, las cuáles pueden ser ordenadas dependiendo del criterio del periodista, punto que será tocado más adelante. Uno de los órdenes más comunes es el de la "pirámide invertida". Curtis MacDougall subraya las ventajas de esta metodología, ya que facilitan la lectura, satisfacen la necesidad de la curiosidad natural de la gente, facilitan el montaje de la página y facilitan la redacción del titular (citado en Fernandez \& Mora, 2012, p. 35). Asimismo, el criterio del periodista es uno de los elementos más importantes para estructurar la nota, pues es quien decide a qué se le dará mayor enfoque. Charnley sostiene que

la noticia no es la muerte de un dictador o la elección de un presidente, o la suspensión de un partido de fútbol; es el relato que el periodista hace de la muerte, de la votación o del defecto que ha interrumpido una cuenta regresiva en Cabo Kennedy. (citado en Fontcuberta, 1980, p. 9)

El relato periodístico debe cumplir siempre con un rol informativo, siendo el factor inmediatez un aliado importante para mantener actualizados a los lectores; sin embargo, esta característica también puede jugarles en contra. Actualmente, la necesidad de compartir rápido una noticia suele generar una falta de verificación, ocasionando que se pueda compartir información falsa. El sensacionalismo, por su parte, también es una característica que se ha complementado con los titulares clickbait, pues al momento de buscar captar la atención del usuario, se utiliza una interrogante o una exclamación para generar curiosidad en este. Así, se atenta contra el criterio tradicional del titular informativo, ya que puede engañar al lector para persuadirlo a entrar a la nota.

A partir de lo expuesto, se contrasta el orden jerárquico tradicional con el orden que se le da a las notas periodísticas con titular clickbait publicadas en web, demostrando si ha alterado (o no) los criterios de redacción periodística, en busca de una mayor lectoría o público al cual acceder en términos de publicidad y marketing. De esta forma, se plantea lo siguiente:

Objetivo general: determinar los efectos del clickbait en los criterios de jerarquización en el ciberperiodismo peruano de radio y televisión. 
Hipótesis general: el clickbait ha tenido efectos negativos en los criterios de jerarquización en el ciberperiodismo peruano de radio y televisión, alterando la estructura para que la respuesta planteada en el titular se encuentre al final de la nota para mantener al lector el mayor tiempo posible en la misma.

\section{El periodismo digital en el Perú}

Los recursos del mundo digital han logrado facilitar la navegación de los usuarios. La llegada de la Internet no solo significó una experiencia más sencilla, sino que permitió una cobertura más completa por parte de los medios de comunicación, siendo la inmediatez uno de los pilares para compartir información. El periodismo informativo en la web ha logrado acoplarse a las nuevas tendencias digitales, donde existen beneficios como los enlaces de hipertexto o el contenido multimedia. Así,

la rapidez con que muchos medios se fueron sumando a la incorporación de versiones en línea y adaptando las características del nuevo medio, obligó a todos los dueños de medios de comunicación tradicionales a actualizarse y destinar personal y pequeñas partidas económicas para organizar sus versiones online. (Sánchez, 2007)

Rodríguez (2009) afirma que los medios de comunicación han necesitado adaptarse a los constantes cambios y avances que presentan las nuevas tecnologías. La transición de los medios al "mundo 2.0" no se dio desde un principio, sino que tuvo un proceso de adaptación para acomodar sus plataformas a estas nuevas facilidades. Ocampo (2017) analiza la evolución del ciberperiodismo y señala que todo fue distinto al inicio: con solo 30 millones de usuarios conectados a la Internet (entre 1994 y 1996) aparecieron los primeros medios digitales, que en ese entonces eran tan solo la replicación digital de los contenidos publicados en la edición impresa de los diarios (Ocampo, 2017, p. 180).

En el caso peruano, fue la revista Caretas el primer medio nacional en adoptar esta nueva tendencia en 1995 (Yezers'ka \& Zeta, 2016). Los primeros diseños de las webs no eran amigables para el usuario, ya que se trataban de copias del medio físico en digital. En el caso de Caretas, durante la primera década el medio no presentó cambios significativos; sin embargo, a partir del 2005, 
implementó el uso del contenido multimedia y los recursos de hipertexto, además de adoptar un modelo empresarial, cobrando por acceder a contenidos informativos (Yezers'ka \& Zeta, 2016, p. 18).

Yezers'ka (2008) emprendió una investigación pionera sobre las primeras plataformas virtuales de los medios de comunicación y qué porcentaje del contenido era original para web o una adaptación del diario impreso, descubriendo que el $70 \%$ de los medios publicaba la edición impresa completa en su web, el $30 \%$ solo trasladaba un porcentaje del diario impreso, y el $20 \%$ colgaba una edición del diario en PDF (pp. 12-13). Además de Caretas, la adaptación de los medios peruanos al mundo digital se dio de manera progresiva. Con el pasar de los años, los diseños web fueron adquiriendo sus propias características, publicando noticias en tiempo real, así como actualizando las que ya se habían compartido en físico.

Radio Programas del Perú (RPP Noticias) fue el primer medio radial en adoptar esta tendencia en 1996. Asimismo, fue de los primeros en aprovechar los recursos multimedia, implementando el contenido sonoro que transmitían por su emisora en las notas que usualmente publicaban en la web (Yezers'ka, 2008, pp. 19-21). Sánchez (2007) afirma que $R P P$ suele basar su contenido en los recursos que obtienen de la radio para elaborar sus notas informativas (p. 41).

Por su parte, el portal de América Noticias fue el primero de los medios televisivos en colocar su contenido en la Internet, al crear su sitio en 1998. Mientras se desarrollaba el mundo digital, este medio de comunicación fue adquiriendo ciertas características, tales como brindar la señal en vivo desde su página web (Yezers'ka \& Zeta, 2016, pp. 25-26). Actualmente, entre otros recursos, difunden reportajes elaborados en sus noticieros y los comparten a través de sus notas web.

\subsection{Características del periodismo digital}

El mundo digital tiene una serie de características que facilitan la navegación de las plataformas que las aplican, así como recursos que vuelven la visita más amigable. Un ejemplo claro es el caso de RPP Noticias, cuya plataforma ofrece la opción de escuchar radio en vivo. Además, generan notas a partir del contenido que recogen de sus programas, así como adjuntar bytes de audio 
que complementan las noticias. Caso similar ocurre con América Noticias, que también ofrece la opción de ver su programación en vivo, incluyéndose los noticieros y otros programas. Del mismo modo, se componen notas a partir del contenido del noticiero, el cual muchas veces se adjunta en la nota. Machado (2000) llega a la siguiente conclusión con respecto al análisis del periodismo digital:

Con la multiplicación de los datos, el usuario de las redes puede utilizar los análisis de los periodistas como una especie de juicio complementario de los eventos. Como el periodismo digital incorpora en un único soporte texto, audio, vídeo es de esperarse que la generación de profesionales que actúa en los nuevos medios expanda sus habilidades en áreas como escritura abstracta, hipermedia y en conocimientos más profundos en el campo conceptual de la comunicación. (p. 349)

Machado (2000) comenta sobre la importancia del uso de estos recursos propios de cada medio, puesto que el valor de un video o un audio para el usuario puede ser crucial al momento de consumir el contenido. Una noticia que contenga este tipo de características se puede volver más atractiva para el lector, logrando que este la comparta o complemente la información que ya posee con contenido audiovisual.

Además de la incorporación de herramientas multimedia, el periodismo digital o "ciberperiodismo" cuenta con una serie de características que benefician la navegación del usuario. La inmediatez es la más importante de estas, porque ahora el periodista tiene la posibilidad de actualizar el contenido de la nota conforme se vayan dando los hechos. Existe una necesidad de obtener la primicia, por lo que los medios están constantemente renovando su contenido para mantener su plataforma lo más actualizada posible. La inmediatez también conlleva al periodista a tener la obligación de escribir la nota y corroborar sus fuentes de la forma más rápida posible. De esta forma, el trabajo de verificación se vuelve más complicado.

Gutiérrez (1999) señala una segunda característica: disponer de un espacio sin límites, que lo diferencia de los diarios físicos, donde el periodista debe trabajar sobre la base de una cantidad específica de caracteres. El redactor es libre de proponer la estructura de su texto y armarlo a su gusto y como considere más importante para relatar los hechos. 
Un tercer rasgo sería la interactividad, que implica la posibilidad de que el usuario sea partícipe de la publicación de la nota al comentar y expresar su opinión (Gutiérrez, 1999). Es por ese motivo que los medios de comunicación han implementado el llamado "periodismo ciudadano" a sus plataformas, siendo los consumidores quienes reportan hechos que podrían ser de interés, a través de redes sociales como Facebook, Twitter o WhatsApp. De esta manera, el periodista se encarga de corroborar información, complementar y elaborarla.

La accesibilidad también es un punto importante del periodismo digital. Cualquier persona con acceso a la Internet puede conectarse a la web de los medios para consultar las últimas actualizaciones. Por ejemplo, en el caso de una cobertura, el usuario tiene la posibilidad de revisar los antecedentes publicados en el medio sobre un tema específico. Esto resulta ser una ayuda importante para el periodista (quien no tendrá que explicar todo nuevamente para contextualizar), mientras que el usuario se encontrará con una estructura más ordenada y tendrá la libertad de escoger qué leerá primero. Además, al ser la actualización constante, puede mantenerse informado sobre los últimos acontecimientos del país y del mundo.

\subsection{Notas periodísticas en la web}

Martínez-Albertos (1974) define a los géneros periodísticos como "las diferentes modalidades de la creación literaria, destinadas a ser divulgadas a través de cualquier medio de difusión colectiva" (p. 70). Según el autor, los orígenes se remontan a los inicios de la prensa escrita, expandiéndose junto a las adaptaciones del periodismo a las nuevas tecnologías. Moreno (2001) los define como "géneros que reflejan el acontecer de un suceso y su interpretación, es decir, la información correspondiente y su comentario o valoración por parte del periodista" (p. 170).

Para Moreno (2001), los géneros narran el hecho a partir del criterio del periodista, quien se encarga de brindar una estructura y decide qué información se debe priorizar. En el periodismo 2.0, la digitalización de los contenidos a otorgado una mayor libertad al periodista para escribir, así como difundir su mensaje (Gutiérrez, 2006, p. 9). Desde la aparición del mundo digital, se ha modificado su estructura y se ha simplificado su contenido, a partir de la 
utilización de enlaces de hipertexto y multimedia. En el presente artículo, se profundiza en el género de las notas periodísticas, las cuales serán objeto de investigación en la parte metodológica.

Las notas periodísticas responden siempre a las preguntas que se hace el periodismo tradicional: ¿quién?, ¿cuándo?, ¿cómo?, ¿dónde? y ¿por qué? (Moreno, 2001, p. 173). Es a partir de allí que el periodista busca redactar la noticia siguiendo un orden de jerarquización donde la parte más importante siempre debe estar resaltada, colocando la información de mayor a menor importancia. Esta estructura de la "pirámide invertida" es la manera más tradicional de ordenar una nota periodística (Salaverría, 1999, p. 13). Este recurso permite que el lector obtenga la respuesta a lo planteado en el titular y si continúa interesado en leer la nota.

Sánchez (2007) sostiene que "la nota informativa busca dar, mediante la concisión, el mayor número de datos con el menor número de palabras" (p. 97). Con esto se refiere a que la información se debe ofrecer de manera corta y resaltando lo más importante, siempre de acuerdo con el criterio del periodista. Asimismo, la información tratada no debe contener la opinión del redactor, a fin de evitar sesgos y juicios valorativos al lector. De esta manera, el lector tiene en sus manos la posibilidad de generar una opinión propia y sacar sus propias conclusiones.

Al investigar sobre la noticia y las notas periodísticas, Fontcuberta (1980) indica que la palabra "interés" es la más recurrente al revisar las definiciones (pp. 10-11). Y es que la nota periodística busca ofrecer una versión más imparcial de las noticias más importantes, colocando los datos más relevantes. En el entorno digital, la utilización del hipertexto funciona como un medio de apoyo para el periodista al momento de redactar la nota, ya que este puede evitar la redundancia y permite ampliar la información de manera más ordenada (Salaverría, 1999, p. 14).

\subsection{El clickbait como herramienta del periodismo digital}

El periodismo digital cuenta con una serie de elementos que facilitan la navegación de los usuarios, ante las necesidades informativas que se adoptaron por las nuevas tecnologías (Rodríguez, 2009, p. 3). Un ejemplo claro es el uso 
de los enlaces de hipertexto, que permiten al lector trasladarse de la nota que lee hacía otra con contenido complementario (Sánchez, 2007, p. 18).

Los enlaces de hipertexto son de los recursos más utilizados en medios de comunicación, pues son una manera sencilla y directa de compartir información adicional, sin necesidad de colocar todo el contenido en una sola nota. Además, permite dosificar el contenido y ofrecer al usuario la oportunidad de conseguir más antecedentes. Algo similar ocurre con el contenido multimedia, que muestra videos o imágenes interactivas que sintetizan información y la hacen más lúdica para el receptor. El contenido multimedia le otorga valor al contenido compartido y lo hace más atractivo para los consumidores de noticias, ofreciendo alternativas comunicativas más llamativas.

Sin embargo, una de las herramientas que ha tenido la mayor expansión en los últimos tiempos ha sido el clickbait, ya que se trata de un recurso digital no tanto para proporcionar información, sino para llamar la atención y, por lo tanto, incrementar las visitas de los usuarios. De esta forma estamos ante un "contenido cuyo objetivo principal es atraer la atención y alentar a los visitantes a hacer clic en un enlace a una página web en particular" (OED, 2018).

La manera en que el clickbait consigue captar la mirada del lector potencial es a partir de titulares que plantean una interrogante. Este estilo ha generado un debate sobre si su aplicación es válida en el contexto periodístico, puesto que ha sido acusado de promover el sensacionalismo. Una de las razones principales de su surgimiento es la adaptación misma del periodismo a un entorno digital.

Es una estrategia que afecta a la calidad informativa al saturar de noticias banales, exageradas y de recursos expresivos que sirven de gancho la información difundida por los medios en redes sociales. En su práctica incurren no solo los medios populares, sino también los medios tradicionalmente considerados serios. (Bazaco et al., 2019, p. 112)

El clickbait surgió de este proceso de adaptación, generando la necesidad de obtener lectores. Esto afectó a los medios en general, volviéndolos susceptibles a la utilización de este tipo de recursos. Bazaco et al. (2019) exploran los conceptos ligados al clickbait y realizan un balance final definiéndolo como un "fenómeno comunicativo dinámico", que responde a ciertas características 
sensacionalistas y de infoentretenimiento, alejándose del periodismo tradicional para buscar clicks (p. 98). García et al. (2017) diferencian un "titular clickbait" de uno tradicional de la siguiente manera.

Sería un titular más periodístico aquel que informar [sic] sobre el hecho principal de la noticia, que tenga valores noticia ... Sería, en cambio, tendente al clickbait aquel que favorece la creación de emociones, de curiosidad frente a la información. (p. 1266)

Para Bazaco et al. (2019), el clickbait es ese recurso que prioriza la interrogante sobre la información, creando emociones que generen curiosidad suficiente al usuario para que este decida entrar a leer la nota. García et al. (2017) llegan a la conclusión de que un titular clickbait no responde a la interrogante que se plantea y carece de sentido, yendo en contra de los criterios tradicionales de información, priorizando la interacción antes que presentar correctamente una noticia (p. 1270). Chamorro (2018) sostiene que se utiliza el clickbait con una connotación sensacionalista, buscando generar reacciones o emociones al lector para que este entre a leer la nota (p. 30).

Learreta (2017) confirma ambas afirmaciones, alegando el uso atractivo del titular para ganar consumidores. Los medios de comunicación también tienen un fin comercial, siendo empresas que buscan un camino viable (p. 19). Esta necesidad ha captado la atención de medios serios y tradicionales, los cuales buscan hacer uso de titulares clickbait para suplir sus necesidades comerciales: "el periodismo se ha adaptado a las lógicas del marketing digital y empieza a desarrollar estrategias de content marketing también en sus redes sociales" (p. 40).

De esta forma, el uso del clickbait se configura como un reflejo del marketing digital en medios informativos, ante la necesidad del medio por generar contenido y ganar dinero. La publicidad, por su parte, no se encuentra dentro del contenido periodístico, sino como parte del entorno del diseño web. Este recurso funciona como una motivación para promover que el usuario consuma la nota, se quede una regular cantidad de tiempo y eso, eventualmente, lo lleve a consumir la publicidad. Esto afecta la jerarquización del periodismo, pues tenemos un titular que ya no cumple con ser informativo y no cuenta lo que se verá dentro del artículo, sino que ahora genera intriga y no se sabe qué se expondrá exactamente en la noticia, promoviendo la desinformación. 


\subsection{Jerarquización de la información}

Para construir la noticia es importante el equilibrio informativo. Para lograr esto, el periodista debe contar con fuentes de información confiables que le permitan construir la nota con veracidad y primando los datos más importantes. Según Acevedo (2012) la noticia parte “de un hecho inédito que dará que hablar y sobre el cual los lectores se formarán una opinión positiva, negativa o neutra" (p. 16). Acevedo (2012) también se refiere al criterio del periodista como detalle importante para la elaboración de la nota. Y es que el periodista es ese filtro que se encarga de corroborar la información para desestimar mentiras construidas sobre los hechos.

Una vez que se define cuál es la noticia, se debe plantear cómo será construida la misma. Existen métodos tradicionales que responden a las ya mencionadas interrogantes de ¿quién?, ¿cuándo?, ¿cómo?, ¿dónde? y ¿por qué? Asimismo, parte del proceso de producción periodística está ligado a la selección de información que se ofrecerá, es decir, la depuración de los datos que se le brinda para que esta cumpla un rol íntegramente informativo (Yanes, 2003, p. 244). Este proceso consiste en seleccionar datos que sean pertinentes para la elaboración de la nota y que sirvan como complemento informativo para el objetivo central de la misma. Luego del proceso de selección, se procede a ordenar el contenido.

La jerarquización de la información en el periodismo informativo depende mucho del criterio del periodista, como se ha mencionado anteriormente. Este es quien decide dónde poner el foco en la noticia y cómo estructurar el hecho noticioso. Un método de jerarquización tradicional es el de la "pirámide invertida", el cual responde a colocar la parte más importante de la noticia al inicio. De esta manera, se irá desmenuzando la información hasta llegar al final de la nota, yendo desde lo más importante hasta lo más prescindible. Salaverría (1999) destaca los beneficios de la pirámide invertida, señalando que facilita el desarrollo para el periodista y la narración de los hechos:

Esta estructura discursiva se caracteriza por comenzar con un sumario del hecho noticioso al que siguen, hasta donde permita el espacio, desarrollos informativos con datos, explicaciones y citas textuales en orden de interés decreciente. Con este formato, los datos se acumulan 
con facilidad puesto que el redactor se preocupa tan sólo por incluir el máximo número de detalles, descuidando otros valores como la ilación narrativa. (p. 14)

Es importante recalcar que el método de jerarquización puede variar dependiendo del género periodístico, porque una crónica o un reportaje no suelen tener la misma estructura que una nota informativa. En todo caso, una vez que se tiene estructurada la nota, se procede a colocar un titular que le indique al lector qué es lo que leerá a continuación. Los titulares periodísticos son aquellos que atraerán la atención del consumidor para decidir si leerá (o no) lo que se está compartiendo. Zorrilla (1996) sostiene que estos se vuelven parte del relato periodístico, pues más allá de buscar ganar lectores, permite comunicar de manera eficaz el contenido de la nota (p. 8). Esta definición coloca al titular como el elemento principal de la nota, el cual llamará al lector a consumir la noticia.

Actualmente, el periodismo digital ha permitido liberar y flexibilizar la redacción, variando la manera de jerarquizar la información. Con la ayuda de enlaces de hipertexto y el contenido multimedia, se ha logrado sintetizar el contenido de distinta manera, pero siempre primando el ya mencionado criterio del periodista. Para el lector, también existe la ventaja de escoger sobre qué quiere informarse y qué noticias va a priorizar de acuerdo a sus gustos e intereses. El periodismo digital también le permite al usuario no sólo leer la nota (según el orden y jerarquía que el periodista quiere ofrecerle), sino que tendrá libertad absoluta para moverse a través de la pantalla para escoger qué verá (Machado, 2000, p. 343).

\section{Metodología}

La investigación es aplicada, pues contiene un análisis de cómo funciona y cómo se desarrolla el clickbait en las notas periodísticas para captar la atención del público. El nivel de la investigación es descriptivo, debido a que analiza minuciosamente cada nota que contenga un titular clickbait para observar la manera en que está jerarquizada, a través de ítems específicos que permitan esclarecer sus características.

El diseño de la investigación es no experimental, ya que no se plantea manipular variables. El objetivo es llevar a cabo un análisis de algo que ya existe y 
se utiliza como recurso en los medios. Para ello, lo que se busca es describir y entender de qué manera el clickbait altera los criterios de jerarquización en el periodismo digital informativo peruano, y cómo esto afecta la tarea periodística.

Con respecto a las técnicas e instrumentos de recolección de datos, se aplica la técnica análisis de contenido mediante el desarrollo del instrumento de matriz de análisis. La muestra está integrada por notas informativas que contengan clickbait en las plataformas digitales del RPP Noticias y América Noticas desde la aparición del "paciente cero" de COVID-19 (6 de marzo), hasta el inicio de la cuarentena (15 de marzo).

A diferencia de otros géneros periodísticos (como el reportaje o la crónica), la nota informativa maneja un cierto tipo de estructura que sigue los lineamientos del llamado "periodismo tradicional", el cual llama a colocar la parte más importante de la información que se desea brindar al inicio de la nota. Para este trabajo, las notas informativas son contenidos interesantes de analizar, pues se podrá observar en qué parte del texto se amplía lo mencionado en el titular y, así, demostrar que lo más relevante no se coloca desde el comienzo, como tradicionalmente sucedía.

Durante la recopilación de información, los medios estudiados utilizaron el clickbait en diferentes ocasiones del periodo de tiempo estudiado; sin embargo, lo hicieron con diferentes géneros periodísticos. Por ese motivo, se decidió examinar sólo las que sean notas informativas y mantengan sus características principales.

\section{Presentación de resultados}

\subsection{RPP Noticias}

El titular de la nota (Tabla 1) contiene una pregunta: presentar una interrogante (con el objetivo de llamar la atención del usuario) hace reconocible la técnica del clickbait para que este revise el texto. Lo que se propone es la continuidad del pago de los maestros frente a la suspensión de clases por la cuarentena. Siguiendo una estructura tradicional (y de acuerdo con la respuesta ofrecida por la nota), el titular pudo ser: "Maestros recibirán sueldo 
con normalidad pese a cuarentena", brindando una afirmación desde el inicio y sin obligar al consumidor a ingresar a la nota para enterarse.

\begin{tabular}{|c|c|}
\hline Titular & $\begin{array}{l}\text { "Coronavirus en el Perú: Tras suspensión de clases, ¿los } \\
\text { maestros recibirán su sueldo?" }\end{array}$ \\
\hline Sentido del titular & $\begin{array}{l}\text { Dar a conocer si los profesores recibirán o no sueldo } \\
\text { durante el estado de emergencia. }\end{array}$ \\
\hline Autor & Redacción. \\
\hline Clickbait & Sí. \\
\hline $\begin{array}{l}\text { Jerarquización de } \\
\text { la información }\end{array}$ & $\begin{array}{l}\text { - } \text { Contexto. } \\
\text { - Reiteración del titular. } \\
\text { - Respuesta al titular. } \\
\text { - Cita de fuente. } \\
\text { - Complemento. }\end{array}$ \\
\hline $\begin{array}{l}\text { Estructura del } \\
\text { discurso }\end{array}$ & Romboide. \\
\hline $\begin{array}{l}\text { Fuentes de } \\
\text { información }\end{array}$ & $\begin{array}{l}\text { - Ministerio de Educación. } \\
\text { - Entrevista a Edgardo Palomino, presidente de la Aso- } \\
\text { ciación de Colegios Privados de Lima (ACOPRIL). }\end{array}$ \\
\hline Sección & “Economía”. \\
\hline
\end{tabular}

La nota sigue una estructura romboide, debido a que empieza contextualizando el porqué de la suspensión de clases y qué preocupaciones se están generando a partir de esto. En el segundo párrafo se reitera la pregunta del titular para que recién en el tercero se ofrezca una respuesta. Se utiliza un comunicado del Ministerio de Educación para aclarar dudas y luego las declaraciones del presidente de la Asociación de Colegios Privados de Lima para complementar la información. Este artículo pertenece a la sección de "Economía" y su autor es anónimo.

El titular de la nota (Tabla 2) emplea una pregunta para introducir la información, rompiendo con los criterios tradicionales de un titular informativo. El público objetivo es amplio, pues se trata del fondo de pensiones de miles de personas que están a la expectativa de las medidas frente al COVID-19 por parte del gobierno y una posible crisis económica. 
Tabla 2

Nota informativa de la web de RPP Noticias

\begin{tabular}{|c|c|}
\hline Titular & $\begin{array}{l}\text { "Coronavirus en Perú: ¿Epidemia afectará a los fondos de } \\
\text { pensiones?" }\end{array}$ \\
\hline Sentido del titular & Confirmar si el COVID-19 afectará el fondo de pensiones. \\
\hline Autor & Redacción. \\
\hline Clickbait & Sí. \\
\hline $\begin{array}{l}\text { Jerarquización de } \\
\text { la información }\end{array}$ & $\begin{array}{l}\text { - } \text { Contexto. } \\
\text { - Reiteración del titular. } \\
\text { - Respuesta al titular. } \\
\text { - Cita de fuente. } \\
\text { - Complemento. }\end{array}$ \\
\hline $\begin{array}{l}\text { Estructura del } \\
\text { discurso }\end{array}$ & Romboide. \\
\hline $\begin{array}{l}\text { Fuentes de } \\
\text { información }\end{array}$ & $\begin{array}{l}\text { - Superintendencia de Banca, Seguros y AFP (SBS). } \\
\text { - Kurt Burneo, economista. }\end{array}$ \\
\hline Sección & "Economía". \\
\hline
\end{tabular}

Nota: RPP Noticias (2020a).

La estructura de la nota es romboide, pues empieza contextualizando el advenimiento de la crisis financiera, seguido de una reiteración del titular para recién dar la respuesta al tema propuesto. El resto de la nota muestra el impacto económico en el fondo de pensiones, permitiendo que el lector se dé una idea de lo que puede ocurrir, basándose en estimaciones. El artículo cita comunicados de entidades y entrevistas a expertos realizadas por medios extranjeros. Esta nota se encuentra en la sección "Economía” y su autor es anónimo.

Como se ha visto en los casos anteriores, en otro titular (Tabla 3) se coloca "Coronavirus en Perú" antecediendo a la interrogante, con la finalidad de introducir el tema. El público objetivo son los padres que no saben cómo proceder con la pensión del colegio de sus hijos, ya que por esos meses no estaba claro si se llevarían a cabo las clases presenciales. 
Tabla 3

Nota informativa de la web de RPP Noticias

\begin{tabular}{|c|c|}
\hline Titular & $\begin{array}{l}\text { "Coronavirus en el Perú: ¿En qué casos los padres po- } \\
\text { drían reclamar el reembolso de la pensión escolar?" }\end{array}$ \\
\hline Sentido del titular & $\begin{array}{l}\text { Mostrar los caso en que sí se podría solicitar el reembolso } \\
\text { de la pensión escolar. }\end{array}$ \\
\hline Autor & Redacción. \\
\hline Clickbait & Sí. \\
\hline $\begin{array}{l}\text { Jerarquización de } \\
\text { la información }\end{array}$ & $\begin{array}{l}\text { - Contexto. } \\
\text { - Reiteración del titular y cita de fuente. } \\
\text { - Respuesta al titular y cita de fuente. } \\
\text { - Cita de experto. } \\
\text { - Complemento. }\end{array}$ \\
\hline $\begin{array}{l}\text { Estructura del } \\
\text { discurso }\end{array}$ & Romboide. \\
\hline $\begin{array}{l}\text { Fuentes de } \\
\text { información }\end{array}$ & $\begin{array}{l}\text { - Entrevista a Edgardo Palomino, el presidente de la } \\
\text { Asociación de Colegios Privados de Lima (Acopril). } \\
\text { - Crisólogo Cáceres, presidente de Aspec. } \\
\text { - Comunicado de Indecopi. }\end{array}$ \\
\hline Sección & "Economía". \\
\hline
\end{tabular}

Nota: RPP Noticias (2020c).

La jerarquización no es tradicional y la respuesta al titular no se encuentra en el inicio. En el primer párrafo hay una contextualización del tema, donde se habla acerca de la cancelación de las clases. En el segundo párrafo se menciona que los padres deben pagar la pensión de marzo y citan a un experto referente al tema. Recién en el tercer párrafo se vislumbra una respuesta, señalando que existen casos en el que los padres sí pueden acceder a un reembolso. El resto de la nota se complementa con las declaraciones del experto, quien aclara algunas dudas adicionales que podrían existir. La nota se encuentra ubicada en la sección "Economía" y su autor es anónimo.

En otra nota se plantea una interrogante en el titular (Tabla 4). Esta vez, el público objetivo es más amplio, debido a que se trata de una noticia de interés nacional. “QQuiénes podrán circular por las calles?” no es un titular informativo: se trata de una pregunta que funciona como gancho para atrapar al lector, por lo que podemos afirmar que esta nota tiene un titular clickbait. El objetivo es informar sobre las restricciones de tránsito que sufriría la ciudadanía. 


\section{Tabla 4}

Nota informativa de la web de RPP Noticias

\begin{tabular}{|l|l|}
\hline Titular & $\begin{array}{l}\text { "Estado de emergencia por coronavirus: ¿quiénes podrán } \\
\text { circular por las calles?" }\end{array}$ \\
\hline Sentido del titular & $\begin{array}{l}\text { Aclarar quiénes pueden transitar los días de Estado de } \\
\text { emergencia. }\end{array}$ \\
\hline Autor & Redacción. \\
\hline Clickbait & Sí. \\
\hline $\begin{array}{l}\text { Jerarquización de } \\
\text { la información }\end{array}$ & $\begin{array}{l}\text { • Contexto. } \\
\text { - Complemento. }\end{array}$ \\
\hline $\begin{array}{l}\text { Estructura del } \\
\text { discurso }\end{array}$ & Romboide. \\
\hline $\begin{array}{l}\text { Fuentes de } \\
\text { información }\end{array}$ & Conferencia de prensa de Martín Vizcarra. \\
\hline Sección & "Actualidad". \\
\hline Nota: RPP Noticias & (2020e). \\
\hline
\end{tabular}

La estructura de jerarquización de la nota es romboide, pues la respuesta a la interrogante se encuentra a la mitad de la nota. Esta comienza contextualizando la situación de los peruanos, comentando información referida al anuncio que el presidente hizo minutos antes. En el segundo párrafo se responde a la interrogante, aclarando dudas de los lectores. Los párrafos adicionales complementan la información, incluyendo una cita del discurso del presidente. La nota se encuentra ubicada en la sección "Actualidad" y su autor es anónimo.

El titular de esta nota de RPP Noticias (Tabla 5) no emplea una pregunta, pero sí juega con la insinuación. Colocar "Coronavirus en el Perú: Estas son las nuevas medidas que dictó el MEF” es inspirar más expectativas que proporcionar información concreta, por lo que podemos afirmar que se trata de un titular clickbait. El objetivo de la nota es anunciar las propuestas del Ministerio de Economía y Finanzas para controlar la economía durante la pandemia. 


\section{Tabla 5}

Nota informativa de la web de RPP Noticias

\begin{tabular}{|c|c|}
\hline Titular & $\begin{array}{l}\text { "Coronavirus en el Perú: Estas son las nuevas medidas que } \\
\text { dictó el MEF". }\end{array}$ \\
\hline Sentido del titular & $\begin{array}{l}\text { Describir las medidas adoptadas por el Ministerio de Econo- } \\
\text { mía para enfrentar una posible crisis frente al COVID-19. }\end{array}$ \\
\hline Autor & Redacción. \\
\hline Clickbait & Sí. \\
\hline $\begin{array}{l}\text { Jerarquización de } \\
\text { la información }\end{array}$ & $\begin{array}{l}\text { - } \text { Contexto. } \\
\text { - Reiteración del titular. } \\
\text { - Respuesta al titular. } \\
\text { - Complemento. }\end{array}$ \\
\hline $\begin{array}{l}\text { Estructura del } \\
\text { discurso }\end{array}$ & Romboide. \\
\hline $\begin{array}{l}\text { Fuentes de } \\
\text { información }\end{array}$ & $\begin{array}{l}\text { Conferencia de prensa de María Antonieta Alva, ministra de } \\
\text { Economía. }\end{array}$ \\
\hline Sección & "Economía". \\
\hline
\end{tabular}

Nota: RPP Noticias (2020d).

La estructura de la nota es romboide, oponiéndose a una jerarquización tradicional como la "pirámide invertida". El foco de la nota (las medidas que se anuncian en el titular) se ubica al final. Primero se lee una contextualización de por qué debe preocupar el coronavirus al futuro de la economía, citando lo dicho por la ministra durante una conferencia de prensa. Luego se reitera el titular, agregando en qué sectores se aplicarían estas reglas. Finalmente, se las enumera. La nota se encuentra en la sección "Economía" y su autor es anónimo.

\subsection{América Noticias}

Esta nota de América Noticias (Tabla 6) presenta una interrogante en el titular: "Coronavirus: ¿Cuáles son las medidas de prevención para los ancianos?". Esta pregunta conlleva a que el usuario (perteneciente a ese grupo etario o que cuenta con familiares que lo sean) sienta la necesidad de leer la nota. El objetivo de este artículo es mostrar cuáles son los riesgos que tiene una persona anciana frente al COVID-19. 


\section{Tabla 6}

Nota informativa de la web de América Noticias

\begin{tabular}{|c|c|}
\hline Titular & $\begin{array}{l}\text { "Coronavirus: ¿Cuáles son las medidas de prevención para } \\
\text { los ancianos?" }\end{array}$ \\
\hline Sentido del titular & $\begin{array}{l}\text { Mencionar qué medidas de prevención podrían implementar } \\
\text { las personas de la tercera edad para evitar contagiarse de } \\
\text { COVID-19. }\end{array}$ \\
\hline Autor & Sin autor. \\
\hline Clickbait & Sí. \\
\hline $\begin{array}{l}\text { Jerarquización de } \\
\text { la información }\end{array}$ & $\begin{array}{l}\text { - } \text { Contexto. } \\
\text { - Reiteración del titular. } \\
\text { - Respuesta al titular. } \\
\text { - Complemento. }\end{array}$ \\
\hline $\begin{array}{l}\text { Estructura del } \\
\text { discurso }\end{array}$ & Romboide. \\
\hline $\begin{array}{l}\text { Fuentes de } \\
\text { información }\end{array}$ & No tiene. \\
\hline Sección & "Actualidad". \\
\hline
\end{tabular}

Nota: América Noticias (2020f).

En este caso, la nota no sigue un orden jerárquico tradicional, sino todo lo contrario. En lugar de proponer la respuesta del titular al inicio de la misma, primero contextualiza la importancia de documentarse sobre el tema. En el segundo párrafo se reitera la pregunta propuesta en el titular, a fin de anticipar lo que se viene. En el tercer párrafo se muestra la propuesta del titular, donde resaltan los cuidados especiales que debe tener una persona que pertenece a una población vulnerable. Al final de la nota, se contextualiza la problemática con cifras y datos complementarios. La nota sigue una estructura romboide: empieza por lo menos importante, coloca el punto principal de la nota a la mitad y cierra con un complemento. Cabe destacar que no cuenta con fuentes de información y se basa íntegramente en un reporte visual que se presentó en el noticiero matutino del canal. La nota se encuentra en la sección "Actualidad", donde se encuentran las noticias más recientes de la web y su autor es anónimo.

América Noticias hace uso de la pregunta en su titular nuevamente: “¿Cómo usar el gel desinfectante contra el coronavirus?" (Tabla 7). El objetivo de la 
nota es dar a conocer recomendaciones para el uso del gel desinfectante; sin embargo, utiliza el signo de interrogación para despertar la curiosidad del usuario, en ese momento preocupado por el inicio de la pandemia en nuestro país.

Tabla 7

Nota informativa de la web de América Noticias

\begin{tabular}{|l|l|}
\hline Titular & “CCómo usar el gel desinfectante contra el coronavirus?" \\
\hline Sentido del titular & Enseñar a usar correctamente el gel desinfectante. \\
\hline Autor & Sin autor. \\
\hline Clickbait & Sí. \\
\hline $\begin{array}{l}\text { Jerarquización de } \\
\text { la información }\end{array}$ & $\begin{array}{l}\text { - Contexto. } \\
\text { Respuesta al titular. }\end{array}$ \\
\hline $\begin{array}{l}\text { Estructura del } \\
\text { discurso }\end{array}$ & Rombonto. \\
\hline $\begin{array}{l}\text { Fuentes de } \\
\text { información }\end{array}$ & Entrevista al Dr. Sebastian Arrieta, médico radiólogo. \\
\hline Sección & "Útil e interesante”. \\
\hline
\end{tabular}

Nota: América Noticias (2020b).

La nota sigue una estructura romboide. En el primer párrafo se contextualiza la situación peruana respecto a la llegada del COVID-19. En el segundo se reitera la interrogante del titular y es resuelta. A partir de allí se complementa la información con la cita de una fuente, quien explica y valida las recomendaciones que deben ser seguidas. La sección "Útil e interesante" de América Noticias se caracteriza por compartir este tipo de información. Su autor es anónimo.

La interrogante se vuelve a hacer presente en otro titular de América Noticias (Tabla 8). Esta vez se hace mención de los "mitos", relacionándolos con el coronavirus. La nota busca aclarar las interrogantes, lo cual hace parcialmente en el segundo párrafo. El uso y la construcción de la pregunta permiten concluir de que se trata de un titular clickbait. 


\section{Tabla 8}

Nota informativa de la web de América Noticias

\begin{tabular}{|c|c|}
\hline Titular & $\begin{array}{l}\text { "Coronavirus: ¿Cuáles son los mitos y verdades del } \\
\text { covid-19?" }\end{array}$ \\
\hline Sentido del titular & $\begin{array}{l}\text { Solucionar las consultas más usuales referentes al } \\
\text { COVID-19. }\end{array}$ \\
\hline Autor & Sin autor. \\
\hline Clickbait & Sí. \\
\hline $\begin{array}{l}\text { Jerarquización de } \\
\text { la información }\end{array}$ & $\begin{array}{l}\text { - Contexto y Respuesta al titular. } \\
\text { - Cita de la fuente. } \\
\text { - Complemento. }\end{array}$ \\
\hline $\begin{array}{l}\text { Estructura del } \\
\text { discurso }\end{array}$ & Romboide. \\
\hline $\begin{array}{l}\text { Fuentes de } \\
\text { información }\end{array}$ & Entrevista a Patricia Pimentel, vocera de EsSalud. \\
\hline Sección & "Actualidad". \\
\hline
\end{tabular}

Nota: América Noticias (2020e).

La jerarquización tiene una estructura romboide, ya que la noticia se inicia contextualizando la preocupación sobre el coronavirus y que es necesario aclarar las dudas con especialistas para que tener ideas y respuestas objetivas. Al final del primer párrafo, se coloca una de las respuestas a las interrogantes, la cual se complementa en la segunda parte. Allí se coloca una cita de la entrevistada (vocera de una entidad pública que tiene reputación suficiente para dar un testimonio fiable y resolver las dudas del público lector). La nota culmina con recomendaciones ofrecidas con la especialista citada, lo cual permite ofrecer una idea más clara de lo que la población debe hacer para evitar contraer el virus. El artículo está ubicado en la sección "Actualidad” y su autor es anónimo.

Otra nota (Tabla 9) engloba un sondeo realizado por América Noticias y que fue publicado en la edición central de su noticiero. Se incluye una pregunta en el titular que anticiparía los testimonios de ciudadanos para combatir el coronavirus y evitar posibles contagios. 


\section{Tabla 9}

Nota informativa de la web de América Noticias

\begin{tabular}{|c|c|}
\hline Titular & $\begin{array}{l}\text { "Coronavirus: ¿Qué hacen los peruanos para prevenir posi- } \\
\text { bles contagios?" }\end{array}$ \\
\hline Sentido del titular & $\begin{array}{l}\text { Sondeo a ciudadanos sobre medidas que toman para salir a } \\
\text { realizar las compras en plena pandemia. }\end{array}$ \\
\hline Autor & Sin autor. \\
\hline Clickbait & Sí. \\
\hline $\begin{array}{l}\text { Jerarquización de } \\
\text { la información }\end{array}$ & $\begin{array}{l}\text { - Contexto. } \\
\text { - Respuesta al titular. } \\
\text { - Complemento. }\end{array}$ \\
\hline $\begin{array}{l}\text { Estructura del } \\
\text { discurso }\end{array}$ & Romboide. \\
\hline $\begin{array}{l}\text { Fuentes de } \\
\text { información }\end{array}$ & Sondeo a ciudadanos. \\
\hline Sección & "Actualidad". \\
\hline
\end{tabular}

Nota: América Noticias (2020a).

La jerarquización mantiene una estructura romboide: inicia contextualizando la situación al inicio de la pandemia en el país. En ese mismo fragmento se reitera lo propuesto en el titular, anunciando que se van a difundir las sugerencias de ciudadanos de a pie para prevenir los contagios. En el segundo párrafo empiezan a responder lo propuesto en el titular a partir de las declaraciones recabadas. Al tratarse de una información de un público inexperto, el medio coloca recomendaciones de expertos para complementar la nota; sin embargo, no lo reconoce como tal, sino lo llama "autoridad", pero no se coloca el nombre ni cita a alguna entidad que pueda contrastar la información de los testimonios. La nota se encuentra en la sección "Actualidad" y su autor es anónimo.

El titular (Tabla 10) contiene una pregunta. Este indicativo ya nos demuestra que su objetivo es generar incertidumbre y, por ende, podemos considerarlo como un titular clickbait. La nota busca mostrar algunos datos de lo que pueden hacer los padres con sus hijos durante el periodo de confinamiento. 


\section{Tabla 10}

Nota informativa de la web de América Noticias

\begin{tabular}{|c|c|}
\hline Titular & $\begin{array}{l}\text { ¿Qué hacer con los niños en casa en tiempos de corona- } \\
\text { virus?” }\end{array}$ \\
\hline Sentido del titular & $\begin{array}{l}\text { Actividades para realizar con los niños en casa y promover } \\
\text { su enseñanza. }\end{array}$ \\
\hline Autor & Sin autor. \\
\hline Clickbait & Sí. \\
\hline $\begin{array}{l}\text { Jerarquización de } \\
\text { la información }\end{array}$ & $\begin{array}{l}\text { - } \text { Contexto. } \\
\text { - Reiteración del titular. } \\
\text { - Respuesta al titular. }\end{array}$ \\
\hline $\begin{array}{l}\text { Estructura del } \\
\text { discurso }\end{array}$ & Piramidal. \\
\hline $\begin{array}{l}\text { Fuentes de } \\
\text { información }\end{array}$ & Información extraída del diario argentino Clarín. \\
\hline Sección & "Útil e interesante". \\
\hline
\end{tabular}

Nota: América Noticias (2020c).

La estructura del texto es piramidal, pues empieza contextualizando la situación que atraviesa el Perú. El siguiente párrafo busca reiterar lo mencionado en el titular, planteando el fin de la época escolar y la actividad que necesitan los niños para combatir el confinamiento. Finalmente, se enumera cada una de las opciones propuestas por el medio para responder al titular. Al final de la nota, se coloca que el texto se trata de un contenido del Clarín, de Argentina. La nota se encuentra en la sección "Útil e interesante" del medio y su autor es anónimo.

Una vez más se utiliza una pregunta en otro titular de América Noticias (Tabla 11). El uso de la interrogación evidencia el uso del clickbait. El objetivo de la noticia es brindar una guía adecuada para evitar que los lectores sean engañados por contenidos falsos (fake news). 


\section{Tabla 11}

Nota informativa de la web de América Noticias

\begin{tabular}{|c|c|}
\hline Titular & “¿Cómo evitar caer en noticias falsas sobre el coronavirus?” \\
\hline Sentido del titular & Guía para evitar las Fake news en diferentes redes sociales. \\
\hline Autor & Sin autor. \\
\hline Clickbait & Sí. \\
\hline $\begin{array}{l}\text { Jerarquización de } \\
\text { la información }\end{array}$ & $\begin{array}{l}\text { - Contexto. } \\
\text { - } \text { Complemento. } \\
\text { - Reiteración del titular. } \\
\text { - Respuesta al titular. }\end{array}$ \\
\hline $\begin{array}{l}\text { Estructura del } \\
\text { discurso }\end{array}$ & Piramidal. \\
\hline $\begin{array}{l}\text { Fuentes de } \\
\text { información }\end{array}$ & Cita de infectóloga Isabel Casetti al portal argentino Infobae. \\
\hline Sección & "Útil e interesante". \\
\hline
\end{tabular}

Nota: América Noticias (2020d).

La estructura es piramidal, pues la nota empieza contextualizando la realidad nacional y cómo el pánico ocasionado por la pandemia puede generar que las personas crean cualquier tipo de información compartida en redes. El siguiente párrafo complementa lo señalado anteriormente con ejemplos de cómo la propagación de noticias falsas puede generar que el público tome medidas exageradas, tales como el desabastecimiento de productos en supermercados. Finalmente, se realiza un balance de las principales redes sociales para demostrar cómo se puede evitar caer en noticias falsas. La nota se encuentra ubicada en la sección "Útil e interesante” y su autor es anónimo.

\section{Discusión de resultados}

\subsection{RPP Noticias}

En la Tabla 1, RPP Noticias emplea una pregunta en su titular, utilizándose como un gancho para atraer al lector. Nuevamente se aprovechan de la incertidumbre por un tema de interés para generar expectativas antes de ingresar 
a la nota. Un punto a favor es el uso correcto de las fuentes, pues responden a la interrogante del titular en todos los aspectos posibles, para profesores de colegios públicos y privados. Es importante señalar que RPP Noticias utilizó contenido recabado en su plataforma radial para escribir la nota. La jerarquización romboide del artículo también fomenta que el usuario se quede durante un tiempo leyendo la información. La respuesta al titular se encuentra en el tercer párrafo, antecedida por una contextualización del tema. La nota termina con información complementaria que podría ser de interés. La nota está firmada por "Redacción", por lo que no cuenta con un autor reconocido.

En la Tabla 2 se emplea la pregunta en el titular como método para captar lectores. Como en el caso anterior, RPP Noticias lo utiliza para alimentar la necesidad de entrar a la nota. El uso del clickbait se puede ver de manera explícita al hacer uso de signos de interrogación, yendo en contra del método tradicional que es más directo y no juega con insinuaciones. La jerarquización vuelve a verse afectada por una estructura romboide, teniendo que llegar al tercer párrafo para dar con la respuesta a la interrogante del titular. Antes se debe pasar por el contexto y, otra vez, por el titular para llegar a una solución. La información complementaria aporta al contenido, pero no se utiliza ninguna fuente propia (conseguida por el medio) para construirla, por lo que se puede considerar un artículo "volteado", basado de otros medios o entidades. Un detalle importante es la autoría de la nota, pues no está firmada por un autor en específico, sino por "Redacción".

En la Tabla 3 RPP Noticias emplea una pregunta en su titular. Como en los casos anteriores, colocar "Coronavirus en el Perú" antes de la pregunta es para informarle a los usuarios que la noticia estará relacionada al tema, pues si apareciese la pregunta sola, no se sabría el contexto. El clickbait está de manera explícita en el uso de los signos de interrogación, causando intriga y necesidad del lector para entrar a la nota. La jerarquización se ve alterada para mantener al usuario la mayor parte del tiempo en la nota. Recién en el tercer párrafo se ven indicios de una respuesta a la nota, la cual se complementa a partir de allí. El contenido importante no está desde el inicio, como debería ser de manera tradicional. Por otro lado, la autoría es anónima, pues firman con "Redacción".

En la Tabla 4, de acuerdo con el contenido anteriormente colocado, podemos definir que RPP Noticias mantiene una constante de utilizar preguntas en sus titulares como estrategia para conseguir lectores. La jerarquización no 
es tradicional. RPP Noticias ha utilizado una estructura romboide colocando la respuesta al titular en la parte media de la nota. Primero contextualizó la situación con contenido que ya es conocido. La ansiada solución a la pregunta está basada en una cita realizada por el presidente durante el mensaje a la nación en el que anunció el inicio de la cuarentena, siendo esta la única fuente que utilizan y complementan. La nota es firmada por "Redacción", por lo que tampoco cuenta con un autor.

Si bien el titular de la Tabla 5 no utiliza interrogación, sí juega con la insinuación al colocar "Estas son las medidas...". No ofrece una información directa, sino que juega con el contenido para generar incertidumbre. Se vuelve a colocar "coronavirus", pues es la manera de comprobar que la noticia se refiere al tema en mención. La jerarquización mantiene un estilo romboide, yendo en contra de la "pirámide invertida". El contenido importante (lo que le da respuesta al titular) se encuentra ubicado en la parte media de la nota. En cambio, al inicio contextualiza y luego reitera el titular. El resultado es una enumeración de puntos tocados por la ministra durante su discurso de presentación. La nota termina con un complemento del contenido ofrecido. El artículo está firmado por "Redacción”, por lo que no cuenta con un autor.

\subsection{América Noticias}

En la Tabla 6, el titular cumple con los requisitos de ser clickbait. El estilo que usa América Noticias para llamar la atención es utilizar un tema que va a ser relevante para los usuarios y (en lugar de promoverlo con un titular tradicional y directo) lo envuelve en una interrogante para crear la necesidad de acceder a la nota. La respuesta a la pregunta del titular, por otro lado, tampoco se encuentra al inicio de la nota, como tradicionalmente sucedía. Tenemos que ir hasta el tercer párrafo para recién encontrar lo que se busca desde el inicio. La estructura romboide de la nota obliga al lector a quedarse más tiempo en el artículo, cumpliendo con unos de los objetivos del clickbait como recurso del periodismo digital. Respecto a la autoría de la nota, no aparece por ningún lado el nombre del responsable.

En la Tabla 7, el uso del signo de interrogación en el titular confirma que es clickbait. Este uso del gancho (a modo de pregunta) es un recurso que ya se ha vuelto común en los medios, sobretodo en este. Nuevamente vuelven a uti- 
lizar un tema importante para la coyuntura, sin utilizar un titular tradicional. La jerarquización también se ve afectada, pues no se ve la respuesta al titular desde el inicio, sino recién en el segundo párrafo, yendo en contra de lo tradicional. Esta nota cuenta con un video, pero no se menciona en el titular, como ocurre en casos similares. Esta característica de colocar el tipo de contenido multimedia que se va a encontrar en el artículo (ya sea video, infografía, galería, etc.) es una práctica común en el uso del clickbait. Se mantiene la tendencia de no firmar la nota.

En la Tabla 8 nuevamente se utiliza una pregunta en el titular, generando curiosidad en el lector y sin ofrecer una idea del contenido real que se ofrecerá en la nota. Más adelante se revela que se utilizó una entrevista a la vocera de una entidad de salud pública, pero eso no se sabe hasta que empieza a leerse la nota, por lo que podemos considerar que no son objetivos en su planteamiento del titular, razón por la cual confirmamos que se trata de un clickbait. La jerarquización no sigue el estándar de una pirámide invertida, sino que utiliza una estructura romboide, colocando lo más importante al medio de la nota, en este caso, la cita del experto. El primer párrafo vuelve a contextualizar la importancia de conocer recomendaciones de médicos especialistas para combatir y controlar el coronavirus, pero (como está planteado en el titular) no se puede saber hasta leer la nota. En el segundo párrafo se realiza la cita del entrevistado, revelando la respuesta y complementando la información ofrecida. El autor de la nota es anónimo.

En la Tabla 9, la pregunta se hace presente (una vez más) en un titular de América Noticias. Esta vez proponen una interrogante que indica las actividades que realizan los peruanos para combatir el coronavirus, sin proponer mayor información al respecto. Se utiliza la palabra "coronavirus" antes de la pregunta para validar que el contenido a ser compartido será sobre la pandemia, por lo que generará más curiosidad en el lector, buscando adquirir más medidas de prevención. La jerarquización es romboide, sin seguir los parámetros tradicionales de la "pirámide invertida". El primer párrafo contextualiza la situación, señalando el susto de los peruanos por la incertidumbre que genera la pandemia. La nota (elaborada sobre la base de un sondeo y a un reportaje que salió en el noticiero del medio) utiliza los testimonios como fuente para realizar el contenido, sin ser expertos en el tema. Por otro lado, intentan validar la información señalando la opinión de expertos, pero sin nombrarlos, generando más dudas que respuestas. La nota culmina con un llamado a la 
calma en caso se presenten síntomas de la enfermedad. No existe firma del autor por ninguna parte.

En la Tabla 10, América Noticias mantiene la tendencia de utilizar una pregunta en su titular. Este método de utilizar el clickbait (para generar incertidumbre a los usuarios) se ha vuelto común en el medio, como se ha evidenciado en las notas estudiadas anteriormente. Esto genera que incite al lector con las razones equivocadas para entrar a la nota, llamado por la curiosidad y no por la información que necesita leer. Esta nota sigue una estructura piramidal, respondiendo a la pregunta de la interrogante en el último párrafo. Primero contextualiza la situación de los niños, luego reitera el titular y, finalmente, enumera las posibilidades que tienen los padres para realizar actividades con sus hijos. La nota fue editada a partir de un artículo publicado en otro medio (Clarín) y no contiene fuentes reales de información que corroboren que lo dicho en el artículo es algo válido. Si bien la nota es de contenido ligero, aun así, utiliza un titular con interrogante para lograr su cometido de atraer a los cibernautas curiosos. Se mantiene una tendencia a no firmar los contenidos.

El titular de la Tabla 11 incurre nuevamente al uso de la pregunta para generar incertidumbre. Esta tendencia mantiene el uso del clickbait en los titulares de América Televisión. Asimismo, coloca "coronavirus" para evidenciar por dónde estará orientado el contenido. La nota mantiene una estructura piramidal, yendo en contra de la tradicional pirámide invertida. Al inicio se evidencia una contextualización acerca del pánico generado por la pandemia y sus implicancias en el tipo de contenido que se podría ofrecer en los medios. Luego, complementa la información reiterando el titular y colocando ejemplos del tipo de información que suele tergiversar antes de llegar al público. Finalmente, se coloca la respuesta al titular, pero sin citar a ninguna fuente. Se puede asumir que el contenido se ha recabado a partir de los protocolos de seguridad de las principales redes sociales y portales de Internet, pero eso no se realiza de manera explícita al compartir la información. Una vez más no se encuentra al autor de la nota.

\section{Conclusiones}

La llegada de la Internet ha logrado que los medios de comunicación tengan la inmediatez como su primer aliado, permitiendo una cobertura más comple- 
ta de los hechos importantes. En el Perú, los primeros medios en incursionar a este fueron la revista Caretas (1995) y el diario La República (1996). En el caso de prensa y televisión, RPP (1997) y América Televisión (1998) respectivamente, fueron los primeros en adaptar su contenido a una plataforma digital.

El mundo 2.0 tiene una serie de recursos que buscan facilitarle la navegación a los usuarios. El uso de los enlaces de hipertexto o contenido multimedia (videos o galerías de fotos) se han vuelto comunes y han configurado una experiencia más lúdica con el medio. Por su parte, el clickbait (como recurso propio del mundo 2.0) más que ofrecerle facilidades al usuario, busca llamar su atención para que este tenga necesidad de consumir la nota. Este recurso del mundo digital tiene características sensacionalistas, utilizando frases llamativas y emocionales para generar interés en los consumidores.

En los casos estudiados, se ha evidenciado que tanto RPP Noticias como América Noticias utilizan preguntas en sus titulares, sin llegar a responder de qué tratará la nota, por lo que se evidencia el uso del clickbait. De 11 notas, 10 utilizan el recurso de la interrogación para dar indicios del contenido, pero sin llegar a revelarlo por completo. La estructura de las notas sigue una jerarquización romboide principalmente, es decir, no cumple con las características de una tradicional pirámide invertida. Las notas inician con una contextualización de la situación actual. Luego se reitera el titular y (recién en la mitad) se revela el contenido que busca el lector. El resto del artículo es complementario.

El uso de las citas no es recurrente. Suelen basarse en comunicados para armar el artículo. En ocasiones, citan a expertos, pero no mencionan el nombre o locación de trabajo del mismo (Tabla 9). Por su parte, en el caso de RPP Noticias, las notas estudiadas no fueron firmadas, manteniendo a su autor anónimo ("Redactor"). Asimismo, América Noticias no colocó en ninguna parte de los artículos analizados quién fue el responsable de escribirlos.

Podemos afirmar que el clickbait ha alterado los criterios de jerarquización en la prensa radial y televisiva, pues todas las notas utilizan una estructura romboide al momento de ser elaboradas. Ello evidencia que el clickbait ha tenido una influencia negativa, pues hace uso de un titular poco informativo, cuyo objetivo principal no es dar con objetividad la noticia, sino obligar al 
usuario a leerla. Otra característica, al hacer uso de una estructura romboide, es provocar que el lector se quede el mayor tiempo posible en la nota para que el usuario llegue a consumir la publicidad que ahí se le ofrece. Más que un recurso periodístico, el clickbait es un recurso del marketing, negocio al que más medios de comunicación intentan adentrarse para subsistir.

\section{Fuentes consultadas}

Acevedo, K. (2012). El periodismo y la sentencia de Alberto Fujimori por los crímenes de La Cantuta y Barrios Altos. Cobertura y tratamiento de la noticia en los diarios: El Comercio, Trome, La República, El Popular, Correo y Ajá [Tesis de maestría]. PUCP. http://dspace.sanagustin. edu.pe:8080/xmlui/handle/123456789/203

América Noticias. (2020a, Marzo 6). Coronavirus: ¿Qué hacen los peruanos para prevenir posibles contagios? https:/www.americatv.com. pe/noticias/actualidad/coronavirus-que-hacen-peruanos-prevenir-posibles-contagios-n407592

América Noticias. (2020b, Marzo 9). ¿Cómo usar el gel desinfectante contra el coronavirus? https://www.americatv.com.pe/noticias/util-einteresante/como-se-usa-gel-antibacterial-coronavirus-n407569

América Noticias. (2020c, Marzo 13). ¿Qué hacer con los niños en casa en tiempos de coronavirus? https://www.americatv.com.pe/noticias/util-e-interesante/que-hacer-ninos-casa-tiempos-coronavirus-n408272

América Noticias. (2020d, Marzo 13). ¿Cómo evitar caer en noticias falsas sobre el coronavirus? https:/www.americatv.com.pe/noticias/util-einteresante/coronavirus-como-combatir-desinformacion-n408255

América Noticias. (2020e, Marzo 14). Coronavirus: ¿Cuáles son los mitos y verdades del covid-19? https://www.americatv.com.pe/noticias/actualidad/coronavirus-cuales-son-mitos-y-verdades-covid-19-n408065 
América Noticias. (2020f, Marzo 14). Coronavirus: ¿Cuáles son las medidas de prevención para los ancianos? https://www.americatv.com.pe/noticias/actualidad/coronavirus-cuales-son-medidas-prevencion-ancianos-n407816

Bazaco, A., Redondo, M., \& Sánchez-García, P. (2019). El clickbait como estrategia del periodismo viral: concepto y metodología. Revista Latina de Comunicación Social, 74, 94-115. http://www.revistalatinacs. org/074paper/1323/06es.html

Chamorro Poy, E. (2018). Clickbait: definición y análisis de su presencia en El Español y El Huffington Post [Tesis de licenciatura]. Universidad de Valladolid. http://uvadoc.uva.es/handle/10324/34049

Fernandez-Merino, P., \& Mora, J. (2012). Periodismo y teoría de la literatura: una mirada conjunta. OGIGIA. Revista electrónica de estudios hispánicos, 11, 33-45 https://doi.org/10.24197/ogigia.11.2012.33-45

Fontcuberta, M. (1980). Estructura de la noticia periodística. Editorial ATE.

García, B., Gallur, S., \& López, X. (2017). El uso del clickbait en cibermedios de los 28 países de la Unión Europea. Revista Latina de Comunicación Social, 72, 1261-1277. http://www.revistalatinacs.org/072paper/1218/RLCS-paper1218.pdf

Gutiérrez, E. (1999). Periodismo electrónico. Comunicación de masas del siglo XXI. Revista Latina de Comunicación Social, 24. http://www. revistalatinacs.org/a1999adi/12evelyn.html

Gutiérrez, S. (2006). El reportaje inteligente en Internet. Aportes teórico-metodológico para la discusión. Revista Latina de Comunicación Social, 61. http://www.revistalatinacs.org/200613Siglic.pdf

Learreta, J. (2017). Clickbait, redes sociales y medios de comunicación Análisis del uso del clickbait y las distintas estrategias de marketing digital en las redes sociales de los principales medios de comunicación españoles [Tesis de licenciatura]. Universidad Jaime I, España. http:// repositori.uji.es/xmlui/handle/10234/172817 
Machado, E. (2000). La estructura de la noticia en las redes digitales (Un estudio de las consecuencias de las metamorfosis tecnológicas en el periodismo) [Tesis doctoral]. Universidad autónoma de Barcelona, España. http://www.gjol.net/wp-content/uploads/2012/12/2000_machado_tese.pdf

Martínez-Albertos, J. (1974). Redacción periodística. Los estilos y los géneros en la prensa escrita. Editorial ATE. https://www.insumisos. com/LecturasGratis/martinez\%20albertos\%20jose \%20-\%20redaccion\%20periodistica.pdf

Moreno, P. (2001). Los géneros periodísticos informativos en la actualidad internacional. Revista Latina de Comunicación Social, 43. http:// www.revistalatinacs.org/2001/latina43julio/35moreno.htm

Ocampo, M. (2017). Ciberperiodismo en evolución. Anuario Electrónico de Estudios en Comunicación Social "Disertaciones", 10(1). https://revistas.urosario.edu.co/xml/5115/511552608012/index.html

Oxford English Dictionary, OED. (2018). Clickbait. https://en.oxforddictionaries.com/definition/clickbait

Rodríguez, R. (2009). Periodismo digital en el entorno 2.0: nuevas fórmulas periodísticas para llegar y fidelizar usuarios. Actas del I Congreso Internacional Latina de Comunicación Social. http://www.revistalatinacs.org/09/Sociedad/actas/32Ruth_Rodriguez.pdf

RPP Noticias. (2020a, Marzo 10). Coronavirus en Perú: ¿Epidemia afectará a los fondos de pensiones? https://rpp.pe/economia/economia/ coronavirus-en-peru-epidemia-afectara-a-los-fondos-de-pensiones-noticia-1250580?ref=rpp

RPP Noticias. (2020b, Marzo 11). Coronavirus en el Perú: Tras suspensión de clases, ¿los maestros recibirán su sueldo? https://rpp.pe/ economia/economia/coronavirus-en-el-peru-tras-suspension-suspension-de-clases-afectara-los-bolsillos-de-los-maestros-noticia-1250865?ref=rpp 
RPP Noticias. (2020c, Marzo 11). Coronavirus en el Perú: ¿En qué casos los padres podrían reclamar el reembolso de la pensión escolar? https://rpp.pe/economia/economia/coronavirus-en-el-peru-en-que-casos-los-padres-podrian-reclamar-el-reembolso-la-pension-escolar-noticia-1250895?ref=rpp

RPP Noticias. (2020d, Marzo 13). Coronavirus en el Perú: Estas son las nuevas medidas que dictó el MEF. https://rpp.pe/economia/econo$\mathrm{mia} /$ coronavirus-en-el-peru-estas-son-las-nuevas-medidas-que-dicto-el-mef-noticia-1251359?ref=rpp

RPP Noticias. (2020e, Marzo 15). Estado de emergencia por coronavirus: ¿quiénes podrán circular por las calles? https://rpp.pe/peru/actualidad/covid-19-estado-de-emergencia-por-coronavirus-quienes-podran-circular-por-las-calles-noticia-1251767?ref=rpp

Salaverría, R. (1999). De la pirámide invertida al hipertexto: hacia nuevos estándares de redacción para la prensa digital. Novática. Revista de la Asociación de Técnicos de Informática, 142, 12-15. https://dadun. unav.edu/bitstream/10171/5186/4/de_la_piramide_invertida_al_hipertexto.pdf

Sánchez, L. (2007). Evolución del periodismo digital peruano análisis de los casos: rrp.com, comercioperu.com, panamericana.com y terra.com [Tesis de licenciatura]. Universidad Peruana de Ciencias Aplicadas. http://hdl.handle.net/10757/273393

Yanes, R. (2003). La noticia y la entrevista. Una aproximación a su concepto y estructura. Universidad de La Laguna.

Yezers'ka, L. (2008). Tendencias de los diarios digitales en Perú. Revista Latina de Comunicación Social, 63, 71-82. http://www.revistalatinacs. org/_2008/07/latina_art754.pdf

Yezers'ka, L., \& Zeta, R. (2016). Veinte años de medios digitales en el Perú. $\mathrm{https}$ ://issuu.com/revistadecomunicacion/docs/informe_veinte_a_ os_de_medios_digi 
Zorrilla, J. (1996). El titular de la noticia [Tesis doctoral]. Universidad Complutense de Madrid, España. http://eprints.ucm.es/1865/1/T20884.pdf 